\title{
HUMAN DETECTION ROBOT FOR DISASTER MANAGEMENT
}

\author{
Gopika D, Hrithik Sivadasan, Pooja Jiresh, Sucheta G S \\ B M S College of Engineering (Affiliation to VTU) \\ Bangalore, India \\ S Y Pattar \\ Associate Professor, \\ BMS College of Engineering (Affiliation to VTU) \\ Bangalore, India
}

\begin{abstract}
The aim of this project is to provide a prototype of practical design to build a simplified version of a Human detection robot which has to be implemented during calamities to find the casualties. Humans can be used for rescuing people in these areas, but due to high risk of earthquakes and building collapses it is not possible to send human rescue teams in these areas. Thus an affordable high technology equipment which makes this risky job quicker and safer is needed for the hour, which has been described in this paper. It is a simple, yet efficient equipment to indicate casualties and help them with immediate access to first aid.
\end{abstract}

Keywords-Arduino Uno Microcontroller, Robot Chassis, PIR (Passive Infrared) sensor, buzzer, LCD (Liquid Crystal Display), LED(Light Emitting Diode), wires, DC motor, Breadboard, Buzzer

\section{INTRODUCTION}

A unique passive Infrared sensor is used in our design that receives infrared rays that are emitted from humans. When a human body emits infrared radiation of micron wavelength it will be received and manipulated by the PIR (Passive infrared sensor). Once a human target is located the system has to give an alert which may help to identify and localize the victim location as soon as possible. The major part of circuit design is the 'Human detection module' which will be used for carrying out the search activity.

\section{IMPLEMENTATION}

The Arduino monitors PIR sensor and the program is written and uploaded to Arduino. Whenever a human detection occurs within the range of PIR sensor, the LED switches on and buzzer rings which can be seen by the team. If the PIR sensor generates false alerts, this will also be monitored by the Arduino and considered by the operation team. The team will move the robot in the vicinity, stop it and carry on a human search.

\section{OPERATION}

The rescue robot is carried to the disaster area and connected. The batteries must be completely charged before the operation. Then the robot is powered on and the motor gets activated, which inturn causes the wheels to move. The robot is then moved to the vicinity to search for casualties or humans. Whenever humans are detected within the PIR sensor range, LCD displays 'Human Trace Detected', LED glows and buzzer rings all these happen simultaneously. If the LED is ON that means a human casualty is around. The robot stops when the human is detected and moves backward for 10 seconds. PIR sensors can detect humans within the range of 10 meters i.e. 30 feet. The disaster management team makes a consideration plan and enters the calamity area to rescue the victims.

\section{A. Arduino Microcontroller}

Arduino Uno is a microcontroller board supported by ATmega328P semiconductor unit. It has 14 digital input/output pins (of which 6 can be used as Pulse Width Modulated outputs), 6 analog inputs, a $16 \mathrm{MHz}$ ceramic resonator, a USB connection, a power jack, and a reset button.

Human detection module of the robot controlled by an Arduino microprocessor. When an individual is present within the range of the sensing element (10 meters) it creates a detection signal (a digital pin goes high) that is processed by Arduino and a (LED signal will glow on to indicate the direction. Here Arduino is used for controlling and coordinating operations in the circuit. 
International Journal of Engineering Applied Sciences and Technology, 2021

Vol. 5, Issue 10, ISSN No. 2455-2143, Pages 193-199

Published Online February 2021 in IJEAST (http://www.ijeast.com)

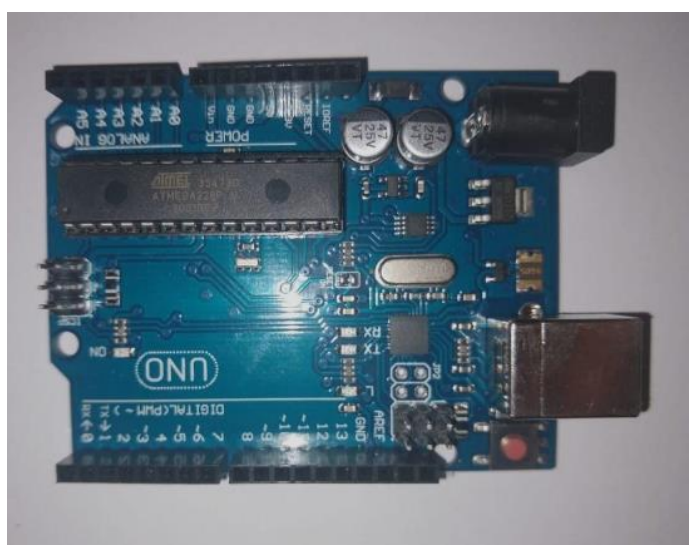

Fig 1. Arduino Uno Microcontroller

\section{B. PIR Sensor}

Passive infrared sensor (PIR sensor) is a sensor that detects infrared radiation, emitting from objects kept within its operating range. They work entirely by detecting infrared radiation (radiant heat) emitted by or reflected from objects and humans.

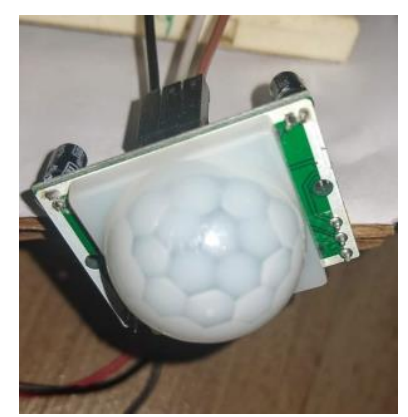

Fig 2. PIR Sensor

\section{C. $\quad$ LCD display, LED}

An LCD is a Liquid Crystal Display module which is used to display characters. The $16 \times 2$ LCD module is used here. Meaning of $16 \times 2$ is that the module displays 16 characters in a line and there are 2 lines in this module. Here LCD. Here LCD is used for displaying the status of human detection.

LED is abbreviated as Light Emitting Diode and is a two terminal device for indication purpose. It has 2 pins, which will be varying in length. The pin of longer length is the positive pin or anode, the pin of shorter length is called negative pin or cathode.

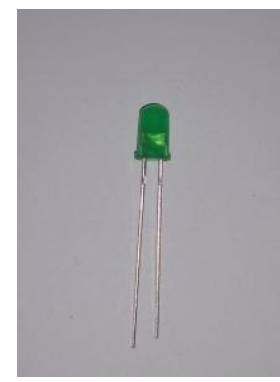

Fig 3 .LED (Light Emitting Diode)

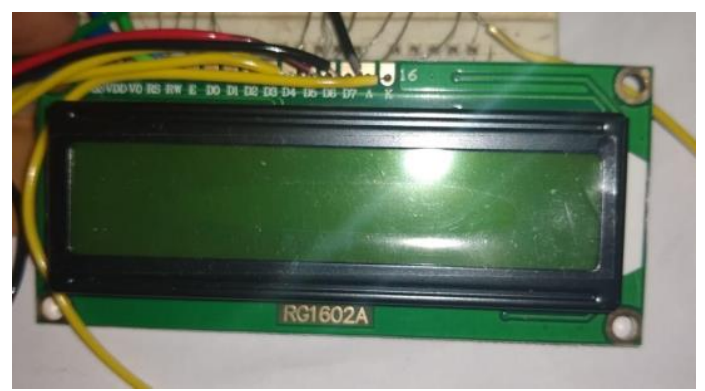

Fig 4. 16*2 LCD Display

D. DC motor

A DC motor is a rotating electrical motor that converts DC electrical energy into mechanical energy. These motors consume electrical power through direct current and convert this electrical energy into mechanical rotational motion. Here DC motors are used for the rotation of robot wheels.

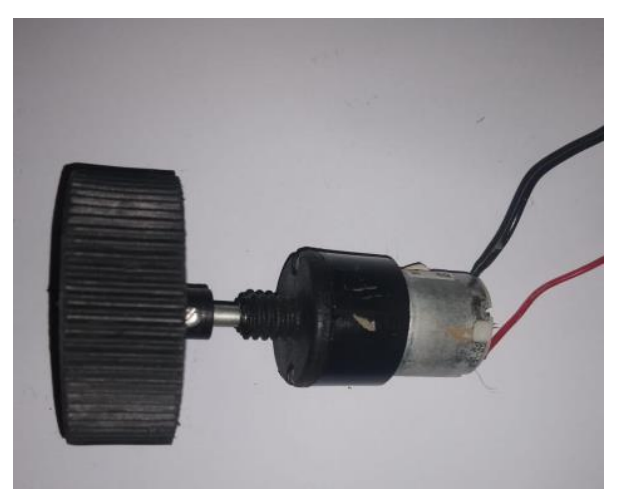

Fig 5. DC motor with robot wheels

\section{E. Battery}

A battery is an integration of one or many cells where the chemical reactions create flow of electrons, which in turn results in production of current. The positive terminal of the battery is called as the cathode and its negative terminal is the anode. The electrons will flow from anode to the cathode through an electrical circuit which will be connected externally. Here we have used a 9 Volt battery for powering up the robot wheels. 
International Journal of Engineering Applied Sciences and Technology, 2021

Vol. 5, Issue 10, ISSN No. 2455-2143, Pages 193-199

Published Online February 2021 in IJEAST (http://www.ijeast.com)

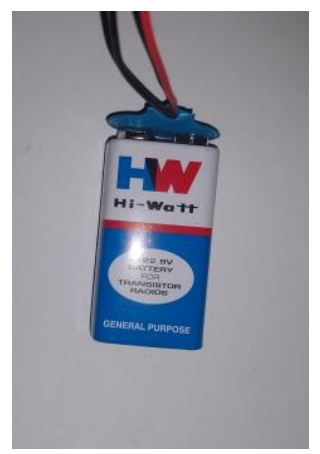

Fig 6.9V Battery

\section{F. Buzzer}

Buzzer is an indication device. It is used in an alarm circuit or any other audio output circuit.

Basically, it converts audio signals into sound signals. Here it is used in parallel with LED to indicate whether human trace is detected or not.

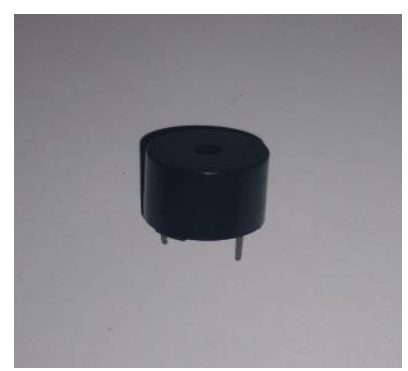

Fig 7 . Buzzer

\section{HUMAN DETECTION MODULE}

\section{Hardware Implementation}

The PIR sensor is powered by Arduino 5V and GND pins. Sensor's data signal pin is monitored using a digital input pin of the Arduino. The entire circuit is powered by a 9V rechargeable battery for extended operation. Because
Arduino has an internal voltage regulator it can be powered from the power connector up to $12 \mathrm{~V}$.

Range of the PIR sensor is 10 meters. Humans or casualties in this vicinity are identified by this sensor. The LED starts glowing when the casualties are detected and the buzzer rings simultaneously. LCD displays that Humans are detected.

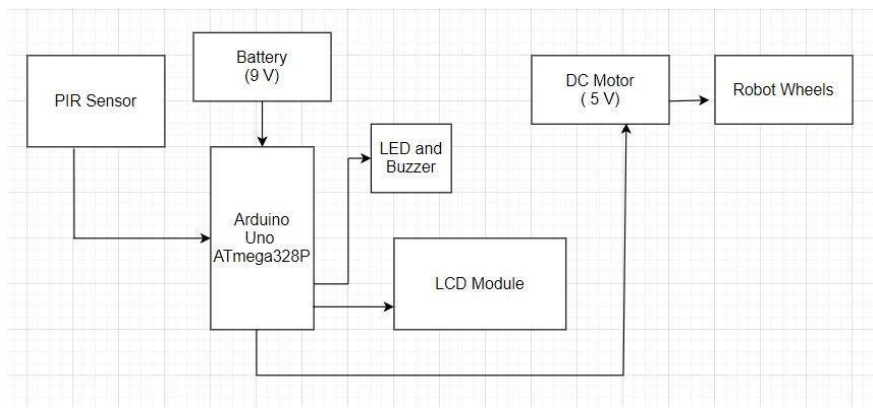

Fig 8. Block diagram of the proposed model

1. Work flow of the process

Initially, the motors receive instructions from arduino and they start moving in the forward direction.

The LCD displays 'Motion and Human Detector' and it starts displaying 'Checking for humans in range'.

When the PIR sensor detects living human beings radiating infrared radiations, the led starts glowing, the buzzer starts ringing.

Then the LCD displays 'Human trace detected'.

This alerts the rescue team and helps them save the person.

Then the motor starts running backward and in different directions to detect more alive human beings.

Until the detection does not happen the lcd displays 'no human in range

The led and buzzer also would not be in an active state.

The process keeps continuing on loop. 
International Journal of Engineering Applied Sciences and Technology, 2021

Vol. 5, Issue 10, ISSN No. 2455-2143, Pages 193-199

Published Online February 2021 in IJEAST (http://www.ijeast.com)

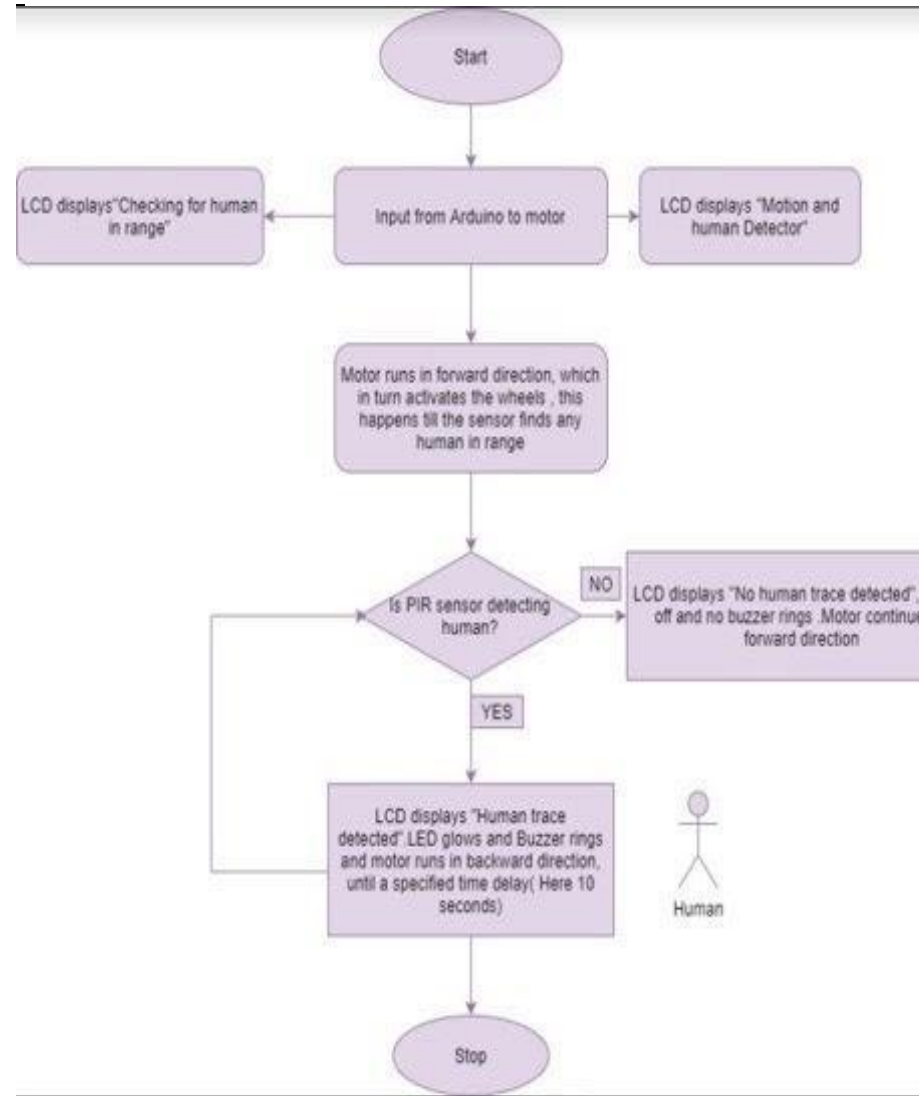

Fig 9. Shows the flow of the model in a diagrammatic way (flowchart)

B. Software Implementation

1. Algorithm for Arduino Uno ATmega328p

\section{Require}

Inputs from PIR sensor

\section{Ensure}

Arduino connected to USB cable

Notions

1. START

2. $\quad$ pirState $=0$;

3. $v a l=0, p=0$;

4. $\quad$ LCD display $=1$;

5. l.clear();

6. LCD display "Motion and Human detector";

7. $\operatorname{delay}()$;

8. LCD display "Checking for human in range",

9. $\quad$ if (pirState $=1)$;

10. LCD display "Human trace detected";

11. $L E D=1$;

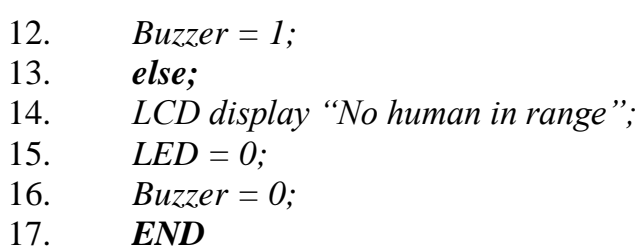

\section{Arduino IDE}

The algorithm is coded in $\mathrm{C}$ language to Arduino IDE including the sensor libraries and then debugged if there are errors.

If it is error free, then the code is burned to the hardware.

Test run is carried out to confirm the working of the circuit.

\section{Working Model of Human Detection Robot}

First, we started with the circuit building. We designed Arduino as input to the motor and the PIR sensor.

LCD display was connected to the resistor to limit the current flowing through it.

Next, the DC motor was connected to the wheels of the Robot chassis.

Connections were made through the wires and the circuit board.

And then we integrated in the Arduino IDE(Integrated Development Environment) software to run the program

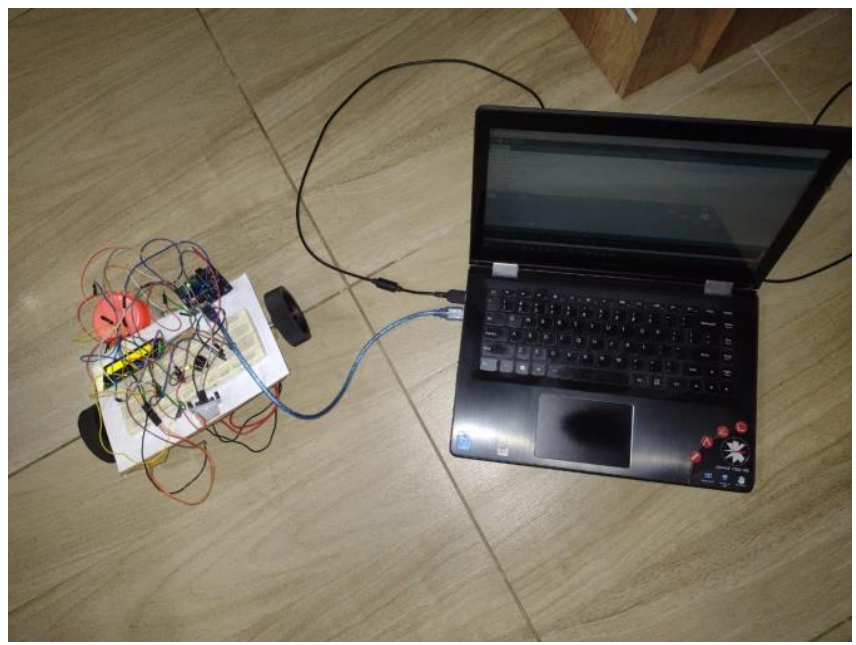

Fig 10. Program debugging and uploading to the hardware 
International Journal of Engineering Applied Sciences and Technology, 2021

Vol. 5, Issue 10, ISSN No. 2455-2143, Pages 193-199

Published Online February 2021 in IJEAST (http://www.ijeast.com)

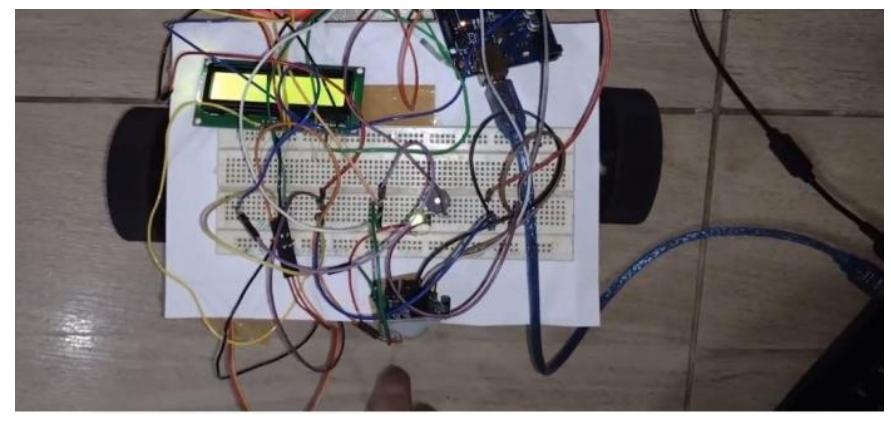

Fig 11. Working model of the Robot

\section{RESULT}

Outdoor passive infrared sensors have a range of 10 meters, and a horizontal range of 108.6 degrees.

The Arduino IDE (Integrated Development Environment) software is debugged and compiled.

During the operation, LCD displays " Motion and Human detector" and after a delay of 20 seconds, PIR sensor gets activated and LCD displays "Checking for humans in range". When there are no human casualties found in the above mentioned range, the LCD module displays " No human detected" and the robot wheels continue to move in forward direction. If there are Human casualties detected, then the LCD displays "Human trace detected", and the robot wheels move in backward direction for a specified delay, here it is set as 10 seconds. This process continues on a loop. Additionally, LED glows and the buzzer rings simultaneously when the PIR sensor detects human casualties. To illustrate the rotation of robot wheels a white patch has been placed on the right wheel to observe it's rotation.

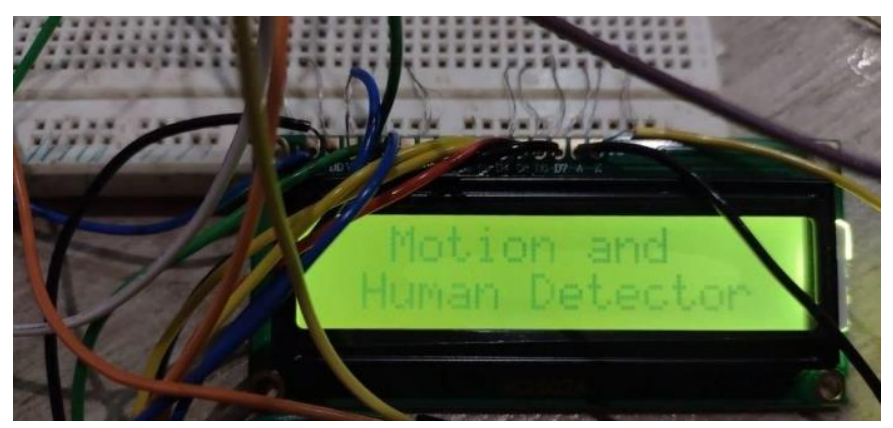

(a)

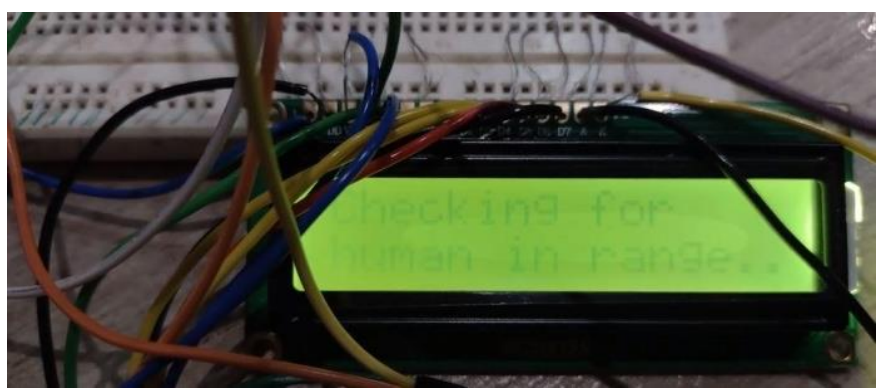

(b)

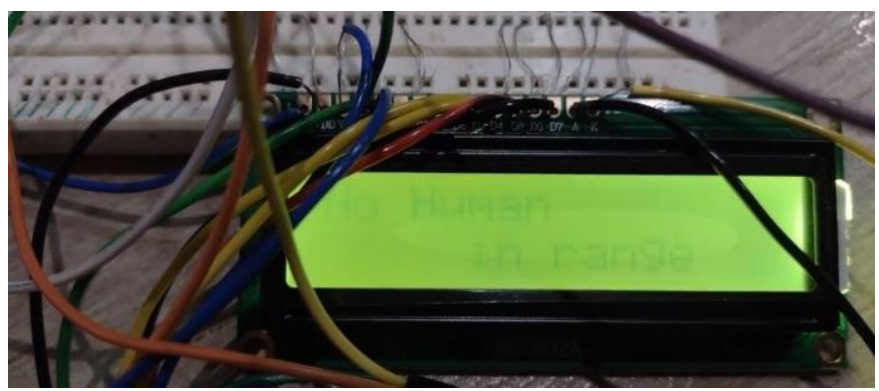

(c)

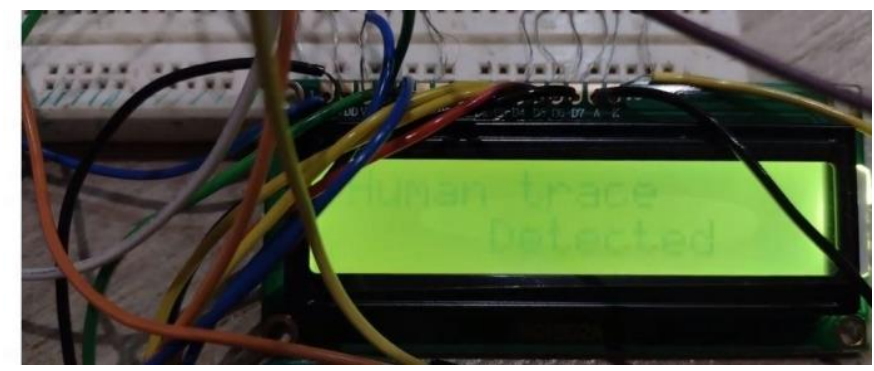

(d)

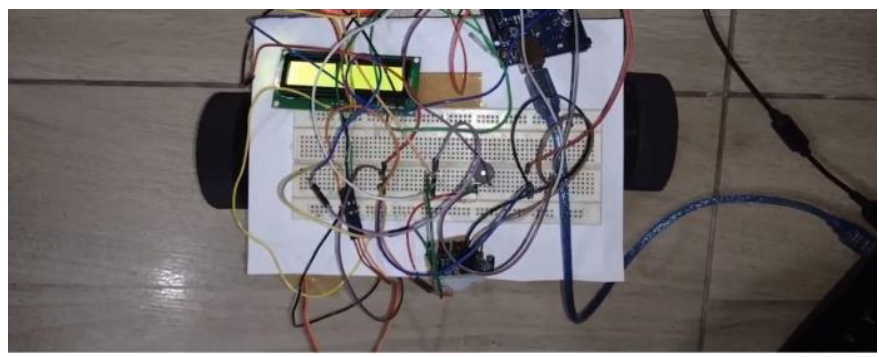

(e) 


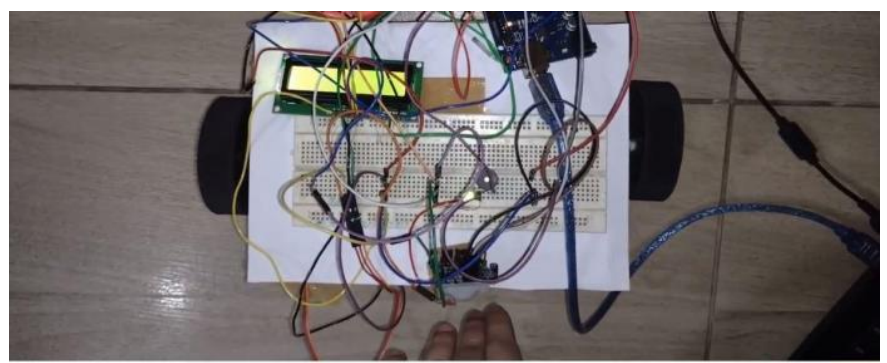

(f)

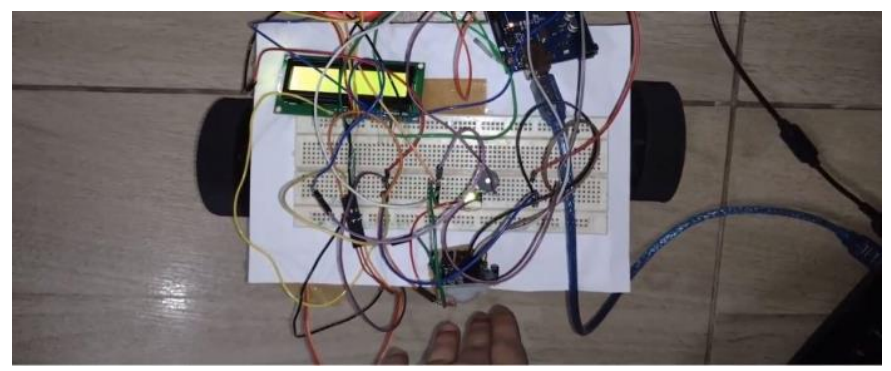

(g)

Fig 12. (a) Zoomed view of LCD displays " Motion and Human Detector" (b) After PIR sensor gets activated when checking for casualties, LCD displays " Checking for human in range..."( c ) When there are no human casualties, LCD displays "No human in range" (d) When PIR sensor detects human ,LCD displays " Human trace detected". (e) When there is no human trace, LED glowing does not occur and wheels continue in forward direction(f) To illustrate, due to the presence of human LED glows and wheels rotate in forward direction(white patch on right wheel)

(g) It has to be observed that white patch on the right side of the wheel has moved backward due to detection of human casualty.

(White patch is for illustration of rotating robot wheels)

\section{CONCLUSION}

A simple, efficient solution for helping rescue workers in disaster management. As it is a wired robot, it has its limitations. Long USB cables are required, and PIR sensors can detect radiation only from living persons etc. This prototype can be further enhanced by making it wireless using Bluetooth or Wi-Fi technology, an infrared camera can be used for visualizing the entire situation before entering the area.This robot can be further integrated with a software application on computers or smartphones to receive notifications. This solution is very reliable, safe, easy to operate and cost effective. Periodic maintenance is not required.

\section{FUTURE SCOPE}

During the emergency and particularly in urban disasters, this project is in good demand. The disasters will be perceived in an exceedingly faster time and therefore the operation will be there for the stake to assist the victims. The invention of this device is user friendly and advanced in technology. This circuit is mainly used in land rovers by making its movement more effective on trough surfaces and in advance this will also be used in drones applying the same circuit and idea with advanced techniques. This circuit and structure is also used with different ideas, in the war field it helps to locate and hit the living enemy targets and a camera on top gives the sight of view of the current situation ahead. By adding voice command it helps to communicate with receiver end selected officers with the sphere war troops. It helps to locate the positions of enemy troops and make easy targeting more optimization which include image processing through this technique it recognizes the victims with their face recognition and fingerprint analysis technique which is directed to the government database to get the whole information about the victim that is our target of rescue. Features like Ultrasonic sensor, Infrared camera for locating the position of the humans. And a technology consisting of Bluetooth or Wi-Fi can be added for a wireless detection robot.

\section{ADVANTAGES}

The human body emits thermal radiation at a wavelength of about ten microns. It's received and manipulated by the PIR sensing element to find human beings. It operates at $5 \mathrm{~V}$ DC. The motion of the person may be detected by checking for a sharp change within the close IR patterns. PIR sensing element varies by ten meters. The Data is received within the Base Station (Control Center). Analyzing the information the Rescue team will take necessary steps to rescue the at bay human beings

\section{APPLICATIONS}

A human detection robot is used around especially during the rescue regimes after a natural calamity such as earthquake, landslide, storms etc. It can also be used in earthquake areas to find victims and also in the army to detect the opponent. Though the detection is done by rescue teams but it is also important to find the stuck humans within the right time.

\section{ACKNOWLEDGEMENT}

We would like to thank BMS College of Engineering, Department of Medical Electronics for encouraging us to proceed with this project. We would also like to express our deep and sincere gratitude to our Professor and the person who guided us in this project, Prof. SY Pattar M.Tech, Department of Medical Electronics Engineering, BMS College of Engineering, Bengaluru, for giving us the opportunity to do research and providing invaluable guidance 


\section{International Journal of Engineering Applied Sciences and Technology, 2021 \\ Vol. 5, Issue 10, ISSN No. 2455-2143, Pages 193-199 \\ Published Online February 2021 in IJEAST (http://www.ijeast.com)}

throughout this research. He has educated us the methodology to hold out the analysis and to present the analysis works as clearly as doable. We would like to extend our gratitude to the faculty in-charge Dr. Joshi Manisha S. It was an excellent learning experience, to understand unmet needs during calamities and we have tried to solve them in an effective manner.

\section{REFERENCES}

[1] Rufaida Shamroukh and Fahed Awad.(2009). "Detection of surviving humans in destructed environments using a simulated autonomous robot"in IEEE Transaction proc. International symposium of mechatronics and its applications, (pp. 1-6)

[2] A. Swapna and K. Archana.( 2017). "A new approach for detecting living human beings in devastating environments using a low cost autonomous robot" in International research journal of engineering and technology, vol. 4, no. 4 (pp. 3078-3081)

[3] M. S. Nagakanya Lakshmi, S. Sridhar, M. Navya, G. V. V. Saikiran, B. Swathi and D. Mohan Krishna.(2017). "Human detection and tracking via radar module robot" in International journal of innovative research in computer and communication engineering, vol. 5, no. 2(pp. 2653-2659

[4] Binoy Shah and Howie Choset.(2004) "Survey on Urban Search and Rescue Robotics," Journal of the Robotics Society of Japan, vol. 22; no. 5(pp. 582-586)

[5] Robin R. Murphy, Vasant Srinivasan, Zachary Henkel, Jesus Suarez, Matthew Minson, J C Straus, Stanley Hempstead, Tim Valdez, Shinichi Egawa.(2013). "Interacting with trapped victims using robots" in Technologies for Homeland Security (HST) 2013 IEEE International Conference(pp. 32-37)

[6] R. Fuksis, M. Greitans and E. Hermanis.(2008). "Motion Analysis and Remote Control System using pyroelectric Infrared Sensors" in IEEE, vol. 6, no. 86(pp. 69-72)

[7] Abid Khan, Ravi Mishra.(2012). "GPS - GSM based Tracking System" in International Journal of Engineering Trends and Technology, vol. 3,no. 2 (pp: 161-169)

[8] S.P. Bhumkar, V.V. Deotare, R.V.Babar.(2012). "Intelligent Car System for Accident prevention using ARM7" in International Journal of emerging Technology and Advanced Engineering, vol. 2, no. 4( pp: 56-78)

[9] Partheeban , R. Rani Hemamalini.(2001). "Vehicular Emission Monitoring using internet GPS and Sensor" International Conference on Environment, Energy and Biotechnology vol. 33 , no. 5(pp: 80 -96)

[10] T C Muralidhara, C. Kanagasabapthi, Siva S Yellampalli.(2017)."Unmanned vehicle to detect alive human during calamity" in Electrical Electronics Communication Computer and Optimization Techniques (ICEECCOT) 2017 International Conference (pp. 84-88)

[11] J. Grönman, J. Viljanen, J. Vihervaara, M. Saari.(2020). "An Open-Source Solution for Mobile Robot Based
Environmental Sensing" in Information Communication and Electronic Technology (MIPRO) 2020 43rd International [12] Convention on ( pp. 966-970)

Schultz Jean, Jill L. Drury and Holly A. Yanco.( 2004). "Evaluation of Human-Robot Interaction Awareness in Search and Rescue" in IEEE (pp. 2327-2332)

[13] D. Greer, P. M. Kerrow and J. Abrantes.( 2002). "Robots in urban Search and Rescue Operations" in Australasian Conference on Robotics and Automation (pp. 25-30)

[14] J. Casper.( 2003). "Human-Robot Interactions during the Robot-Assisted Urban Search and Rescue Response at the World Trade Center" in IEEE (pp. 367-385)

[15] Afak Sekmen, S. Ali, Kazuhiko Kawamura and Mitch Wilkes.(2002). "An Application of Passive Human-Robot Interaction: Human Tracking Based on Attention Distraction" in IEEE, vol. 32, no. 2 (pp. 248-259) 